\title{
An overview on economic machining of hardened steels by hard turning and its process variables
}

\author{
Abhishek Anand ${ }^{1}$, Ajay Kumar Behera ${ }^{1, *}$, and Sudhansu Ranjan Das ${ }^{2}$ \\ ${ }^{1}$ Department of Mechanical Engineering, Siksha O Anusanhan, Deemed to be University, Bhubaneswar 751030, Odisha, India \\ 2 Department of Production Engineering, Veer Surendra Sai University of Technology, Burla 768018, Odisha, India
}

Received: 10 December 2018 / Accepted: 30 January 2019

\begin{abstract}
Producers of machined components and manufactured goods are continually challenged to reduce cost, improve quality, and minimize setup times in order to remain competitive. Frequently the answer is found with new technology solutions. In the recent years, there has been increasing interest in hard turning over grinding for machining of hardened steels in automotive, bearing, mold-die making industries. Hard turning is greatly affected by factors like machine tool, cutting tool geometry and materials, cutting parameters, and cooling methods. There are some issues in the process which should be understood and dealt with such as friction and heat generation at the cutting area that can affect the tool life and surface finish apart from other machining results to achieve successful performance. Researchers have worked upon several aspects related to hard turning and came up with their own recommendations to overcome these problems. This article presents an overview on all the factors that influences hard turning operations performance and is an attempt to give a proper understanding of the process. A summary of the hard turning techniques is outlined and further a comparison of hard turning and grinding is discussed with regard to certain evaluation criteria based on process economical efficiency.
\end{abstract}

Keywords: Hard turning / grinding / machine tool / cutting tool / cooling techniques / cutting parameters

\section{Introduction}

The primary aim for any manufacture is to produce product of high quality with reduced machining time and cost in order to sustain in this competitive machining industries. Traditional machining operations cover a wide range of processes. Today's hardened high-surface steel parts are becoming increasingly important in many engineering applications because of the increasing challenge along with necessity and use of high precision parts to acquire critical performances and due to their excellent essential qualities (high indentation resistance, high value of hardness-to-modulus of elasticity ratio, and low ductility with high abrasiveness) and in particular, these are truly hard-to-cut materials [1]. Traditional method of machining hardened steels involves an expensive and time-consuming technological chain of operations. In this way, machining operations need to continually adopt newer, more efficient, and cost-effective manufacturing approaches to assess the machining of difficult as well as hard-to-cut materials. In recent past, hard turning has

\footnotetext{
* e-mail: ajaybehera@soauniversity.ac.in
}

emerged as solution to overcome these problems of traditional machining operations. Hard turning is a machining process to machine material having hardness value greater than $45 \mathrm{HRC}$ which presents embryonic benefits as well as interests in preference to conventional cylindrical grinding; (1) by without losing the product quality in connection with more flexible, less expensive, and more eco-friendly production, and (2) by employing appropriate and very hard futuristic tool materials under critical machining condition. The advantages of hard turning lead to substantial shortening of the traditional technological chain (forming, annealing, rough turning, heat treatment, and finish grinding). In particular, the hard turning process offers greater process flexibility, reduction of manufacturing cycles and production costs, decrease of setup time and energy consumption, achievement of improved surface integrity and productivity, elimination of hazard cutting fluid by environment friendly finish dry cutting has made this a preferred choice over grinding in many applications from economical and ecological point of views [2,3]. Figure 1 illustrates the economic benefits of production process of hardened steel components, when the process is changing from grinding to hard turning. 


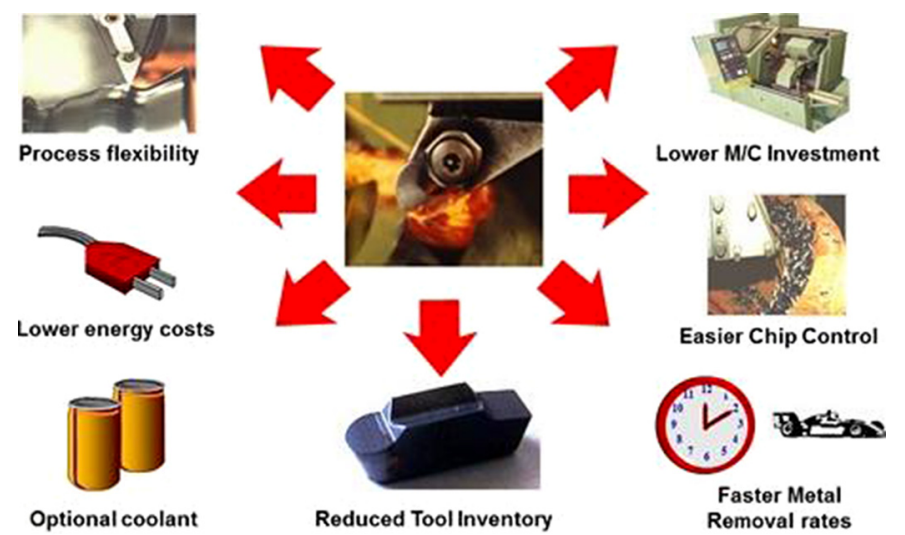

Fig. 1. Economic benefits of hard turning [4].

Hard turning was developed in early 1980s. Machining of hardened steel by hard turning was earlier used in automotive industries for manufacturing of transmission components. Because of wear resistance and improved strength of hardened steel, it has a huge demand in gearshafts, bearings, machine tools, camshafts, punch, and die manufacturing [5]. Tools that are commonly used in hard turning are cubic boron nitride $(\mathrm{CBN}), \mathrm{PCBN}$, ceramics, and carbides. A lot of research work has been done on hard turning suggests that under suitable condition, hard turning can produce components with great dimensional accuracy and better surface finish. In terms of performance, properly configured machine tool can produce a hard-turned part with a surface finish of $0.4 \mu \mathrm{m}$, diameter tolerance of $\pm 3-7 \mu \mathrm{m}$, and size control of the range of $2-5 \mu \mathrm{m}$ [6]. Since hard turning is usually performed dry, i.e. without the use of any coolant, it not only reduces the cost of production but also reduces environmental pollution [7]. Also, machining center used in hard turning consumes less electricity when compared with grinding machine, hence reducing the cost of production. In hard turning, chips can easily be recycled, whereas in grinding operation, the sludge produced needs a costly separation process. Material removal rate is $4-6$ times higher in hard turning when compared with grinding process, also there is reduction in the machining time to about $60 \%$ in this process [8] and especially, if hard turning could be applied to the manufacture of complex parts, manufacturing costs could be reduced by up to $30 \%$, as mentioned by Huang et al. [9]. A qualitative overview is shown in Figure 2.

\section{Process variables in hard turning}

Hard turning process is dependent on machine technology, process technology, materials and tooling technology, cutting technology, and work-holding technology. The key change drivers in the case of hard turning are consisting of various machining process variables, shown in Figure 3. In order to replace cylindrical grinding, the following factors should be considered for successful hard turning which are associated with the machining parameters: (1) a

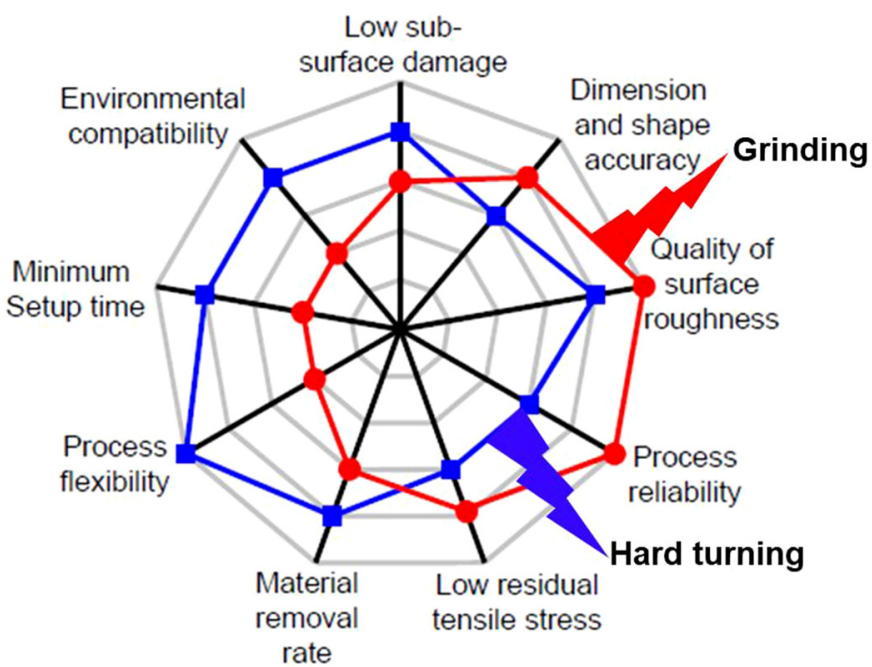

Fig. 2. Qualitative overview of the capability of hard turning and grinding processes [10].

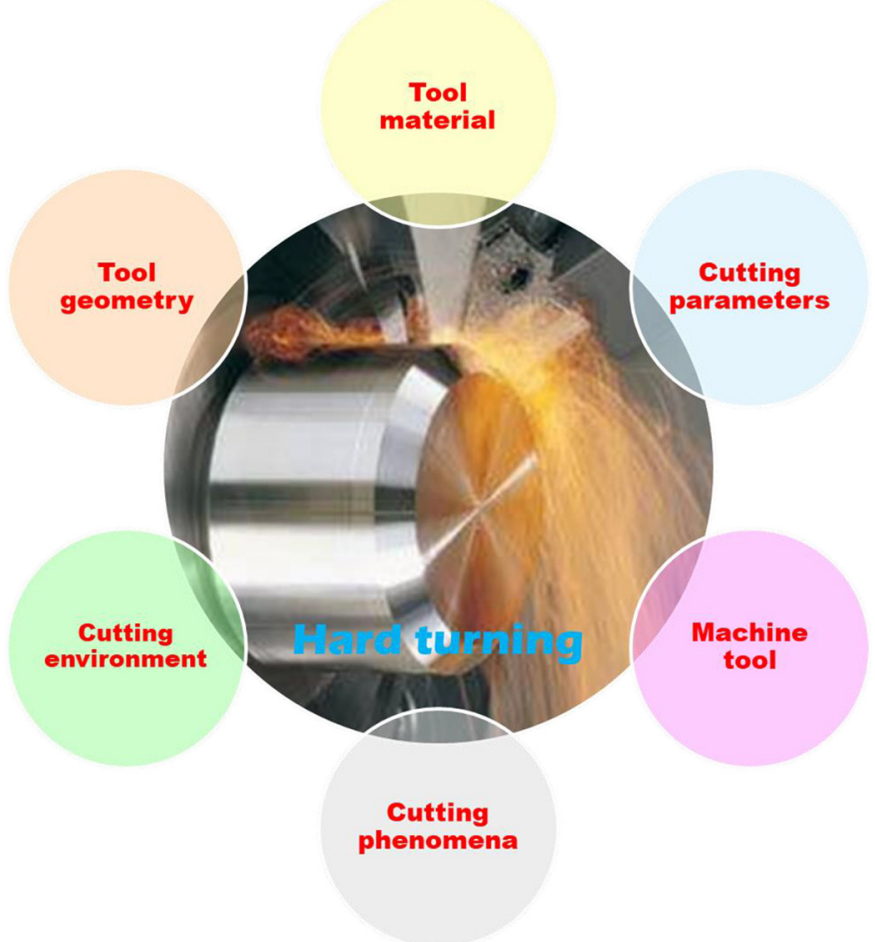

Fig. 3. Influence of different parameters on hard turning.

machine with a high dynamic stiffness, (2) proper work holding devices, (3) a correctly chosen cutting tools and advanced insert materials, (4) high quality cutting edges, (5) rigid tool mounts, (6) appropriate machining parameters, (7) component part rigidity, and (8) chip management and cooling system. 


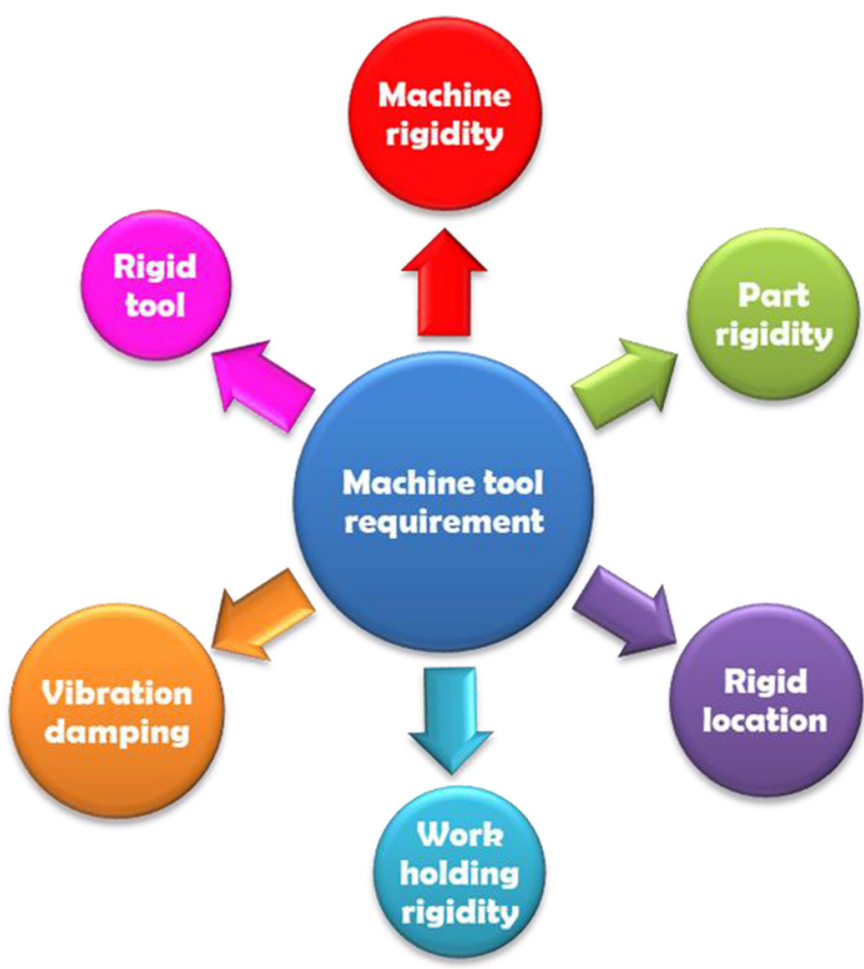

Fig. 4. Machine tool requirements in hard turning process.

\subsection{Machine tool}

Hard turning differs from other conventional machining as it involves the machining of hard material having hardness greater than $45 \mathrm{HRC}$. A high surface speed of $250 \mathrm{~mm} / \mathrm{min}$ or even more than that can be achieved in this turning process, so there is a need of proper machine tool rigidity, high surface speed along with constant surface speed for profile to be finished [11]. The surface finish, size control, and tool life are hugely affected by the dynamic stiffness of machine tool. So any improvement in dynamic stiffness of machine tool will lead to; (a) less operating vibration, (b) considerably improved tool life, (c) considerably improved part quality, (d) higher through-put, and (e) minimum machining parameter adjustments [8]. Large dynamic thrust force is generated while machining of hard material. Poor, stiffness, and damping characteristics of the machine setup lead to the vibration in the machine tool, which affect the accuracy and surface finish of the machined parts. Vibration in machine tool is also the cause of tool failure due to edge fracture. Therefore, not all conventional machine setup and turning centers are suited for hard turning applications. For this, various machine tool attributes should be considered in the machining system for the production of critically hard finished steel component, which are illustrated in Figure 4. Type of structure material greatly influences material removal rate of machine tool, accuracy, and total cost. Common materials used for machine tool are cast iron and steel, although granite and epoxy concrete have been developed and used for structures.

\subsection{Cutting tool for hard turning}

Although hard turning technology is effective and competitive than grinding process with respect to cost, time, and environment yet it encounters problems because of uncertainties related to tool wear pattern and tool life prediction. So, there is a need for suitable cutting tool material with low wearing capabilities as high cutting force is generated. There are enormous varieties of cutting tools used for hard turning. Carbide and ceramic tools are also used for hard turning but the main drawback of these tools is their toughness, these tools are not tough as CBN, and cannot withstand high thermal shock. Among the abovementioned tool materials, most commonly used tool for machining, CBN has a great demand in metalworking industries to machine hardened steel [12], since it is one of the hardest known material and retains its hardness even at high temperature. In comparison to other tools like ceramic or carbide, CBN generally has more wear resistance and shows chemical stability at elevated temperature, and also exhibits properties like high coefficient of thermal conductivity as well as thermal resistance [13]. However, the difficulty associated with compact $\mathrm{CBN}$ processing (high temperature and high pressure) and the high cost of CBN tools have shifted the challenges for hard turning from technological feasibility to economical viability. On the other hand, properties such as low thermal conductivity and low toughness make it unsuitable as tool materials in hard turning of interrupted surfaces. PCBN is obtained either by sintering individual CBN crystals together or bonding with binder materials to form a large mass CBN with a metallic-type binder having excellent abrasion resistance, high thermal conductivity, and higher toughness. PCBN has crystals, which are either sintered with a binder phase usually metallic and ceramic or integrally bonded to a tungsten-carbide substrate. A wide range of grades of PCBN tool can be made by varying the percentage of binder phase and CBN crystal during sintering.

\subsection{Tool geometry for hard turning}

Cutting tool geometry plays a very significant role in hard turning process. Parameters like surface finish, tool wear, heat generation (produced by cutting temperature), chip formation, and cutting force are greatly affected by the tool geometry, as demonstrated in Figure 5. The cutting edge and alignment of the tool face are most important geometric parameters for chip formation. Cutting tool materials used for hard turning have extremely high indentation hardness and high thermal stability. However, they are also brittle and prone to fracture. There is generation of high temperature and force for cutting in hard turning. To overcome these problems, cutting tool is provided with negative rake angle, but if this rake angles value is increased, then it gives rise to high compressive stress (Fig. 6) [14].

Selective research works have been performed to understand the impact of tool geometry design and in its influence to performance in hard turning, as shown in Table 1a. Cutting process is greatly affected by tool's 


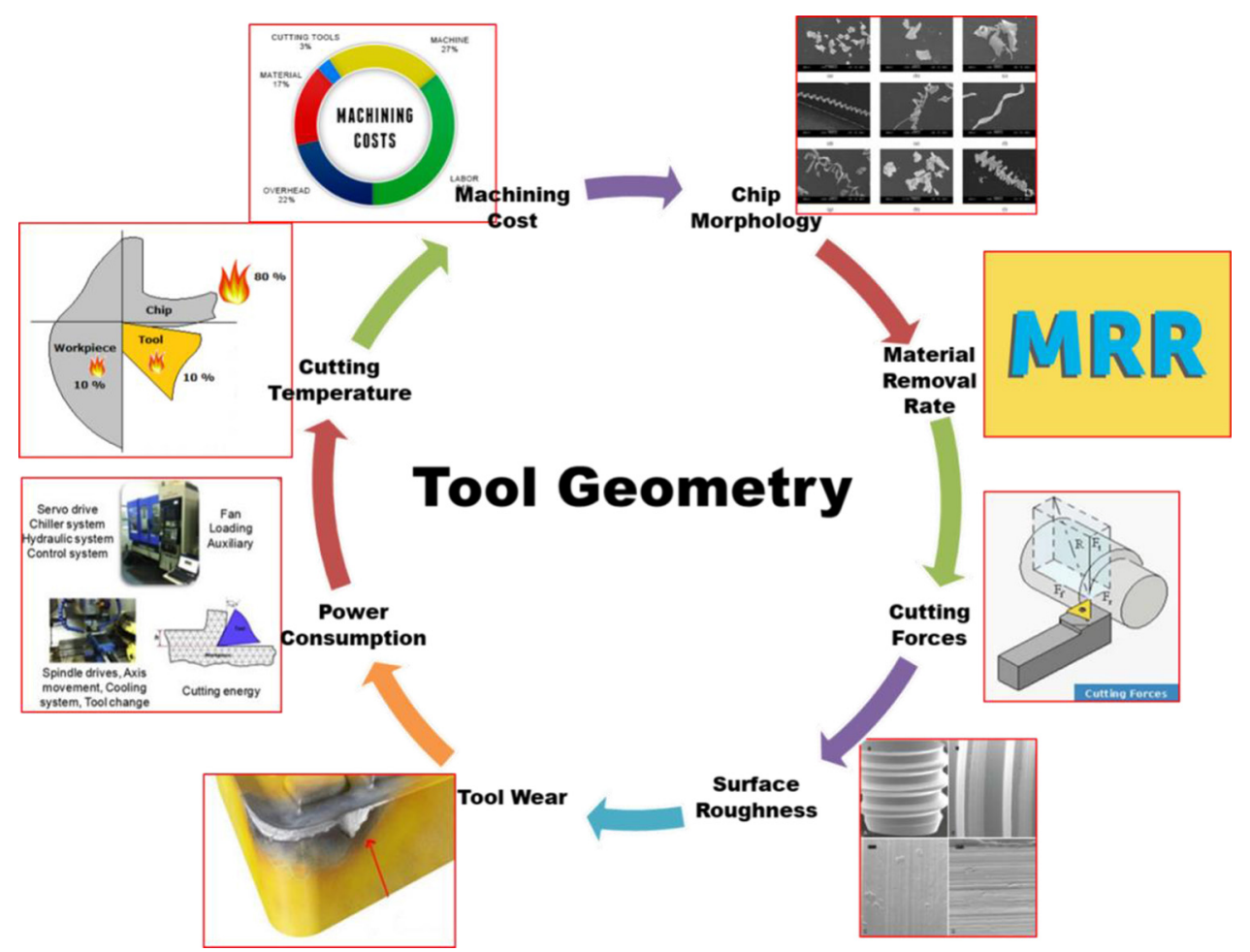

Fig. 5. Technological response parameters affected by tool geometry.

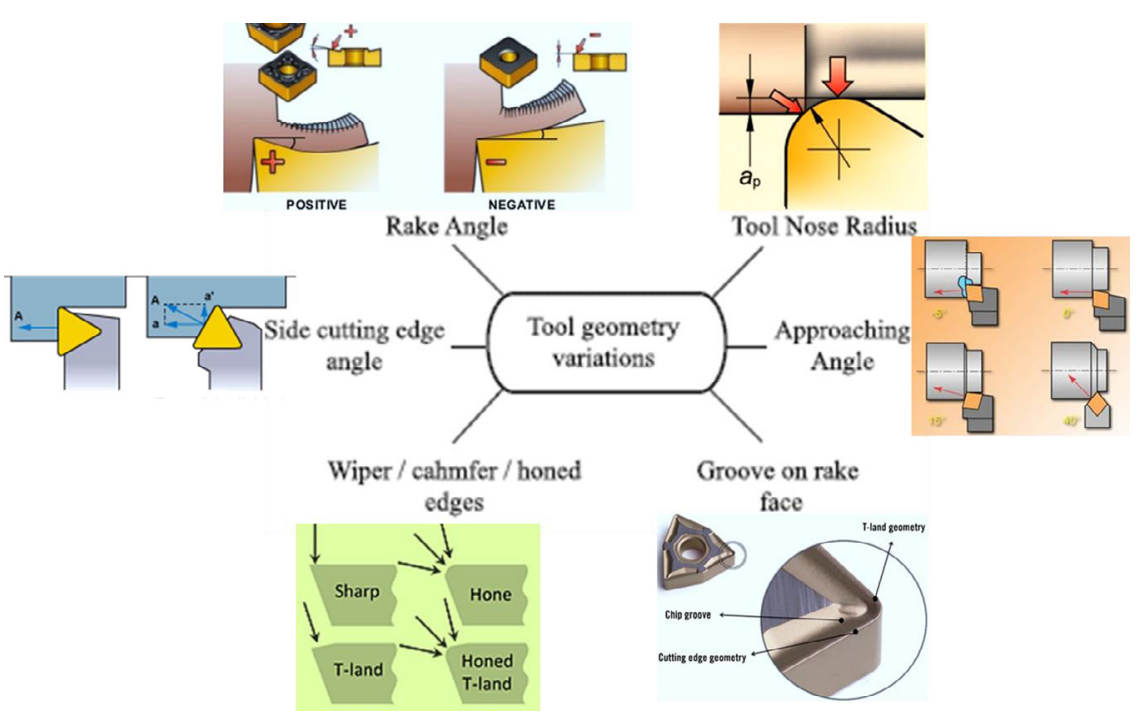

Fig. 6. Illustrations of tool geometry.

cutting edge angle. This is because, for a given feed and depth of cut, cutting edge angle defines the uncut thickness, width of cut, and hence the life of tool [6]. Proper tool nose radius improves the machinability by increasing the tool life, as it can reduce the temperature generation at tool's tip and also increase surface finish, and it also increases strength and cutting edge's life without significant increase in the cutting force [15]. An experimental study investigated the impact of rake angle, entering angle of cutting tool and cutting velocity on machining force, and temperature at tools tip [16]. Larger entering angle produces greater feed force but less thrust force. When the cutting speed was raised, the cutting forces were reduced but the temperature was increased. For the increased positive rake angle, the cutting forces were decreased, which means less force/power is required. Edge hone radius also effects the machining in hard turning as surface roughness is directly proportional to edge hone 
Table 1. Overview of various work and cutting tool materials along with machining process variables for hard turning.

\begin{tabular}{|c|c|c|c|c|c|}
\hline \multicolumn{6}{|c|}{ (a) Tool geometry for hard turning } \\
\hline Guddat et al. [19] & $\begin{array}{l}\text { AISI } 52100 \\
(58-62 \text { HRC })\end{array}$ & PCBN & $\begin{array}{l}\text { Cutting speed, } \\
\text { depth of cut } \\
\text { and feed rate }\end{array}$ & $\begin{array}{l}\text { Insert type, nose } \\
\text { radius, edge radius, } \\
\text { chamfer angle }\end{array}$ & Surface integrity \\
\hline Anthony [21] & $\begin{array}{l}\text { AISI D2 } \\
(55 \mathrm{HRC})\end{array}$ & $\begin{array}{l}\text { Multicoated carbide, } \\
\text { cermet, ceramic } \\
\text { inserts }\end{array}$ & $\begin{array}{l}\text { Cutting velocity, } \\
\text { depth of cut } \\
\text { and feed rate }\end{array}$ & $\begin{array}{l}\text { Nose radius, clearance } \\
\text { angle, rake angle }\end{array}$ & $\begin{array}{l}\text { Cutting force, chip } \\
\text { morphology }\end{array}$ \\
\hline Zerti et al. [22] & AISI D3 & Mixed ceramic tool & $\begin{array}{l}\text { Cutting velocity, } \\
\text { depth of cut, } \\
\text { feed rate }\end{array}$ & $\begin{array}{l}\text { Nose radius, major } \\
\text { cutting edge angle }\end{array}$ & $\begin{array}{l}\text { Surface finish, } \\
\text { tangential force, } \\
\text { cutting force, cutting } \\
\text { power }\end{array}$ \\
\hline \multicolumn{6}{|c|}{ (b) Lubrication and cooling techniques for hard turning operation } \\
\hline Author & $\begin{array}{l}\text { Workpiece } \\
\text { material } \\
\text { and hardness } \\
\end{array}$ & Cutting tool & $\begin{array}{l}\text { Cutting } \\
\text { parameters }\end{array}$ & $\begin{array}{l}\text { Lubrication/cooling } \\
\text { techniques }\end{array}$ & $\begin{array}{l}\text { Machining } \\
\text { characteristic(s) }\end{array}$ \\
\hline $\begin{array}{l}\text { Paul and } \\
\text { Varadarajan [24] }\end{array}$ & $\begin{array}{l}\text { AISI } 4340 \\
(46 \mathrm{HRC})\end{array}$ & $\begin{array}{l}\text { Multilayer coated } \\
\text { carbide insert }\end{array}$ & Cutting speed, feed & $\begin{array}{l}\text { Minimal fluid } \\
\text { application }\end{array}$ & $\begin{array}{l}\text { Tool vibration, cutting } \\
\text { force, temperature, } \\
\text { surface finish, wear } \\
\text { in tool }\end{array}$ \\
\hline Sahu et al. [25] & $\begin{array}{l}\text { AISI } 1015 \\
(43 \mathrm{HRC})\end{array}$ & Carbide insert & $\begin{array}{l}\text { Cutting velocity, } \\
\text { depth of cut, } \\
\text { feed rate }\end{array}$ & $\begin{array}{l}\text { Spray impingement } \\
\text { cooling and } \\
\text { dry environment }\end{array}$ & $\begin{array}{l}\text { Surface roughness, } \\
\text { cutting temperature, } \\
\text { material removal rate }\end{array}$ \\
\hline
\end{tabular}

radius. Thrust force is also affected by edge hone radius. When compared to chamfered edge, the force was smaller in small hone radius [17]. Cutting force and tool life are greatly affected by chamfer angle. With increase in chamfer angle, force in cutting also increases. Another study suggests that in order to get maximum tool life, chamfer angle should be $15^{\circ}$ [18].

\subsection{Cutting fluid and lubrication techniques}

Hardened steel is generally machined dry condition in turning operation [29]. Dry cutting produces smoother surface finish as the heat produced in the cutting zone can make shearing easy by reducing the shear strength of the workpiece [30]. Heat degrades the metallurgical properties of a steel workpiece surface. In hard turning, the largest proportion of heat is evacuated into the chips.
A well-controlled hard-turning operation will rarely cause thermal damage to the part surface. There are two major types of surface damage that can be caused by hard turning are white layer formation and tensile residual stress distribution. Also, the absence of lubricants and fluids reduce cost of machining and also protect labor and environment. However, due to the tool and workpiece friction in hard turning, heat is generated in the cutting zone that can cause effect life of tool, and also increases the thermal damage of the work piece. Reduced tool life can add to the cost of production. Cutting fluid reduces the cutting force, hence reducing the energy consumption and also helps to cool the cutting area and hence increases tool life. Currently, application of cutting fluids by different cooling and lubricating methods have made tremendous effort to improve the efficacy as well as cutting performance of hard turning process, as in 


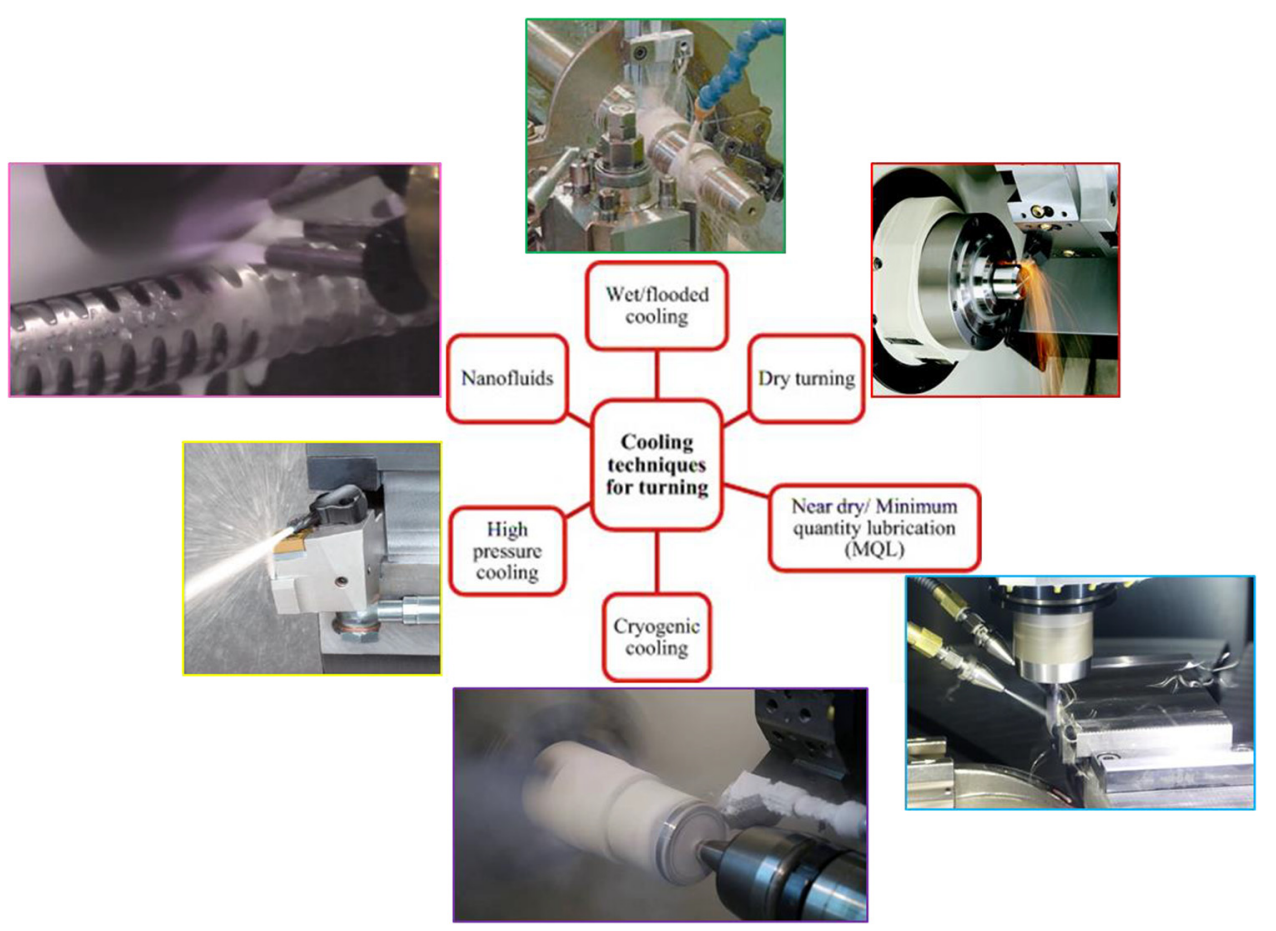

Fig. 7. Cooling techniques in turning hard steel.

Figure 7. However, the application of cutting fluid is restricted because it adversely affects the environment. The problem of cutting fluid can be reduced by using solid lubricants in machining, cryogenic cooling by liquid nitrogen and minimum quantity lubrication (MQL). The solid lubricant, molybdenum di-sulfite $\left(\mathrm{MoS}_{2}\right)$ assisted hard turning, reduces surface roughness and also reduces cutting force as compared dry hard turning condition, but does not greatly affect tool life and wear [31]. Another experiment with minimal fluid application in presence of grease and $10 \%$ graphite resulted in improved cutting performance when compared to dry turning and turning with minimal fluid application [24]. In a study with synthetic oil having $6 \%$ of concentration in water, it was found that cutting in dry environment requires less power and gives better surface finish compared to wet cutting [32]. In an experiment, MQL with vegetable oil, it was concluded that machining with MQL produces improved result than in dry machining as the wear of tool is reduced and also improves tool life [33]. In comparison to MQL assisted hard turning, it was found that there was $23.52 \%$ reduction in cutting temperature in minimal cutting fluid application (MCFA). Also, it is more environment friendly. Machining can also be performed by replacing conventional fluids with cryogenics such as liquid nitrogen or solid carbon dioxide. Hard turning with cryogenics (i.e. cryogenic machining) helps to remove heat during cutting at a faster rate, which helps to increase tool life and also improves the surface finish [34]. Cryogenic cooling can be performed in three ways. One way is by cryogenic pre-cooling of the work piece, where work piece is cooled before machining.
In second way, cooling is performed without the direct contact of cryogenic on workpiece or tool. The third way is by cryogenic spraying at the cutting zone to remove generated heat.

\subsection{Cutting parameters}

Performance of hard turning is greatly influenced by the parameters, i.e., cutting velocity, feed rate, and depth of cut. Various researchers performed hard turning operation to predict machinability on different hardened steels by varying cutting parameters. The purpose of the investigation reported in Suresh and Basavarajappa [35] was to reveal the impact of process parameters: depth of cut, velocity and axial feed rate on flank wear of coated ceramic tool, and surface finish of hardened AISI H13 steel (55 HRC) by conducting the dry turning experiment in CNC lathe. The results indicated that cutting speed predominantly affects tool wear while feed is high influencing factor in surface finish. Rashid et al. [36] revealed that lower feed produces improved machined surface finish, but causes high tool wear, so the choice of a suitable feed must be determined by trade-off between the quality and cost consideration. In a study, Bensouilah et al. [37] observed that growth of surface roughness and cutting force components substantially affected because of cutting parameters namely cutting velocity and feed. During hard turning of AISI D3 steel with uncoated (CC650) and coated (CC6050) ceramic inserts. Regardless the development of flank wear for both cutting tools within control limit $\mathrm{VB}=0.3 \mathrm{~mm}$, surface finish of the machined part was better i.e. did not exceeded $1.6 \mu \mathrm{m}$ (as good as manufactured by grinding), but better surface is 
improved by coated ceramic tool when differentiated to the surface developed by the uncoated ceramic. In an experiment on AISI 52100 steel with CBN tool, it shows that cutting force is directly proportional to feed rate and depth of cut, while decreases with cutting speed. Cutting force was mostly influenced by depth of cut followed by feed and cutting velocity [38]. The higher cutting force at a lower cutting velocity is because of low temperature and formation of built up edge. As cutting velocity increases, flank wear of the tool is also increased leading to immediate deterioration machine surface quality. Surface roughness is greatly influenced by feed as it increases with increase in feed, followed by cutting velocity, whereas depth of cut has negligible impact on surface roughness [39].

\section{Economic potential of hard turning}

For a deeper understanding of the economic benefits of hard turning, it helps to consider a few factors that are sometimes overlooked. These process factors are illustrated below.

The floor space is also an important factor. CNC lathes used for hard turning have less of a foot print than grinders in general. Tool changes can be made in less than $2 \mathrm{~min}$, without the production time losses necessary for a wheel change. Worn PCBN tools may be quickly indexed to a new edge or removed and replaced with new inserts, and do not require truing or dressing to maintain the cutting profile. This flexibility allows for fast, cost-effective production, even in small batches of parts. Further, the structure of most PCBN grades permits for productive machining in difficult conditions, including interrupted cuts, and typically does not require the use of coolant. This helps to keep costs down while eliminating the environmental concern associated with coolant use. Just the cost of coolant and taking care of grinding residues are many times higher than taking care of the dry turning chips and swarf. An additional bonus of hard turning is avoiding cutting fluids. The possibility of dry machining means saving considerable costs otherwise caused by buying, monitoring, treatment, and disposal of cutting fluids.

Apart from further influencing criteria, the material removal rate is a most important economical aspect to evaluate the productivity of a cutting process. For finishing operations, additionally the generated surfaces are of high importance. In finish grinding, high values of material removal rate more than $20 \mathrm{~mm}^{3} / \mathrm{mms}$ can be reached, in finish hard turning, feasible process removal rates are able to achieve values exceeding $200 \mathrm{~mm}^{3} / \mathrm{mms}$. Compared to the material removal rate, the surface rate gains particular importance in the case of machining smaller workpiece diameters with lower over measures and smaller cutting depth. As a typical example, the efficiency of centerlines grinding of roller bearings can hardly be achieved in turning. However, the productivity effect of the turning process in appropriate cases is due to the high form flexibility. Different surfaces and shapes can be machined with one tool. Furthermore, in most cases only one machine tool is needed for outer and inner diameter machining. Because of these advantages, in many applications the machining time can be shortened significantly by hard turning. However, the final determination of machining times and costs can only be made according to a specific production task.

\section{Conclusions}

The overview presented in this paper is a collective work on machining and machinability improvement of hardened steels by hard turning which is being adopted successfully in automotive and mold as well as die making industries. A worthy attention related to hard turning was surveyed in an attempt to find the achievable part quality and technoeconomic efficiency of hard turning process in comparison with grinding on the basis of varying machine tool, tool geometry and material, cutting parameters, and cooling methods. After reviewing a long string of literatures, following conclusions were reported.

- Large dynamic thrust force is generated while machining of hard material. Therefore, the machine tool associated with following attributes like rigid tool, part rigidity, rigid location, high surface speed, etc. should be considered in the machining system which is beneficial for hard turning.

- In complex hard turning process, large volume of heat is generated due to vibration and exhaustive involvement of heavy mechanical load as well as high temperature on cutting tool, therefore ultra-super hard materials such as ceramic and coated carbide tools are useful for hard turning from technological point-of-view, but in most of the cases, CBN tools are used to machine hardened steel as they have high hardness, coefficient of thermal conductivity, and thermal resistance.

- Tool geometry has significant effect on improvement of finish hard turning. As the nose radius increases, improved surface roughness is achieved. With increase in edge hone radius and chamfer angle, cutting force also increases.

- Dry cutting technique is used in hard turning which results the process to be economical and also environment friendly. It can be concluded from the recent studies that use of high-pressure coolant system, cryogenic cooling, and MQL can improve the performance in hard turning operation by enhancing the tool life.

- When compared with grinding, hard turning is technoeconomical because of low setup time, faster cycle time and has a higher material removal rate.

To meet the rapidly growing demands not only for increasing productivity, quality, and economy of conventional materials but also for satisfactory machining of exotic materials, environment friendliness, and ultraprecision finishing lot of possibilities are rapidly generated and remarkable improvements and use of novel but simple techniques and technologies are coming up.

\section{References}

1. K. Nakayama, M. Arai, T. Kanda, Machining characteristics of hard materials, CIRP Ann. Manuf. Technol. 37 (1988) 89-92 
2. H. Tonshoff, C. Arendt, R.B. Amor, Cutting of hardened steel, CIRP Ann. Manuf. Technol. 49 (2000) 547-566

3. W. Grzesik, Machining of hard materials, in: J. Paulo Davim (Ed.), Machining Fundamentals and Recent Advances, Springer-Verlag, London, 2008, pp. 97-126

4. S.G. Larsson, Hard Turning Economics, Technical report. Seco Tool Advanced Material Expert (2015)

5. S. Chinchanikar, S.K. Choudhury, Machining of hardened steel - experimental investigations, performance modeling and cooling techniques: a review, Int. J. Mach. Tools Manuf. 89 (2015) 95-109

6. V.P. Astakhov, Machining of hard materials - definitions and industrial applications, in: J. Paulo Davim (Ed.), Machining of Hard Materials, Springer-Verlag, London, 2011, pp. $1-32$

7. E. Benedicto, D. Carou, E.M. Rubio, Technical, economic and environmental review of the lubrication/cooling systems used in machining processes, Proc Eng. 184 (2017) 99-116

8. Fundamentals of hard turning, GOSIGER. https://www. gosiger.com

9. Y. Huang, Y.K. Chou, S.Y. Liang, CBN tool wear in hard turning: a survey on research progresses, Int. J. Adv. Manuf. Technol. 35 (2006) 443-453

10. F. Klocke, E. Brinskmeier, K. Weinert, Capability profile of hard cutting and grinding processes, CIRP Ann. Manuf. Technol. 54 (2005) 22-45

11. G. Bartarya, S.K. Choudhury, State of the art in hard turning, Int. J. Mach. Tools Manuf. 53 (2012) 1-14

12. H. Aouici, M.A. Yallese, K. Chaoui, T. Mabrouki, J.-F. Rigal, Analysis of surface roughness and cutting force components in hard turning with $\mathrm{CBN}$ tool: prediction model and cutting conditions optimization, Measurement 45 (2012) 344-353

13. A. Hosseini, H.A. Kishawy, Cutting tool materials and tool wear, in: J. Paulo Davim (Ed.), Machining of Titanium Alloys, Springer-Verlag, Berlin, Heidelberg, 2014, pp. $31-56$

14. M. Dogra, V.S. Sharma, J. Dureja, Effect of tool geometry variation on finish turning - a review, J. Eng. Sci. Technol. Rev. 4 (2011) 1-13

15. T. Zhao, J.M. Zhou, V. Bushlya, J.E. Ståhl, Effect of cutting edge radius on surface roughness and tool wear in hard turning of AISI 52100 steel, Int. J. Adv. Manuf. Technol. 91 (2017) 3611-3618

16. H. Saglam, S. Yaldiz, F. Unsacar, The effect of tool geometry and cutting speed on main cutting force and tool tip temperature, Mater. Des. 28 (2007) 101-111

17. W.J. Endres, R.K. Kountanya, The effects of corner radius and edge radius on tool flank wear, J. Manuf. Process. 4 (2002) 89-96

18. J.M. Zhou, H. Walter, M. Andersson, J.E. Stahl, Effect of chamfer angle on wear of PCBN cutting tool, Int. J. Mach. Tools Manuf. 43 (2003) 301-305

19. J. Guddat, R. M'Saoubi, P. Alm, D. Meyer, Hard turning of AISI 52100 using PCBN wiper geometry inserts and the resulting surface integrity, Proc. Eng. 19 (2011) $118-124$

20. A. Davoudinejad, M.Y. Noordin, Effect of cutting edge preparation on tool performance in hard-turning of DF-3 tool steel with ceramic tools, J. Mech. Sci. Technol. 28 (2014) $4727-4736$
21. X.M. Anthony, Analysis of cutting force and chip morphology during hard turning of AISI D2 steel, J. Eng. Sci. Technol. 10 (2015) 282-290

22. O. Zerti, M.A. Yallese, R. Khettabi, K. Chaoui, T. Mabrouki, Design optimization for minimum technological parameters when dry turning of AISI D3 steel using Taguchi method, Int. J. Adv. Manuf. Technol. 89 (2016) 1915-1934

23. H. Aouici, A. Khellaf, S. Smaiah, M. Elbah, B. Fnides, M.A. Yallese, Comparative assessment of coated and uncoated ceramic tools on cutting force components and tool wear in hard turning of AISI H11 steel using Taguchi plan and RMS, Sādhanā 42 (2017) 2157-2170

24. S.P. Paul, A.S. Varadarajan, Performance evaluation of hard turning of AISI 4340 steel with minimal fluid application in the presence of semi-solid lubricants, Proc. Inst. Mech. Eng. Part J: J. Eng. Tribol. 227 (2012) 738-748

25. S.K. Sahu, P.C. Mishra, K. Orra, A.K. Sahoo, Performance assessment in hard turning of AISI 1015 steel under spray impingement cooling and dry environment, Proc. Inst. Mech. Eng. Part B: J. Eng. Manuf. 229 (2014) 251-265

26. M. Mia, N.R. Dhar, Optimization of surface roughness and cutting temperature in high-pressure coolant-assisted hard turning using Taguchi method, Int. J. Adv. Manuf. Technol. 88 (2016) 739-753

27. M. Nouioua, M.A. Yallese, R. Khettabi, S. Belhadi, M.L. Bouhalais, F. Girardin, Investigation of the performance of the MQL, dry, and wet turning by response surface methodology (RSM) and artificial neural network (ANN), Int. J. Adv. Manuf. Technol. 93 (2017) 2485-2504

28. Y. Kaynak, A. Gharibi, Progressive tool wear in cryogenic machining: the effect of liquid nitrogen and carbon dioxide, J. Manuf. Mater. Process. 2 (2018) 31

29. A. Panda, S.R. Das, D. Dhupal, Experimental investigation, modelling and optimization in hard turning of high strength low alloy steel (AISI 4340), Matér. Tech. 106 (2018) 1-17

30. M. Mia, N.R. Dhar, Prediction and optimization by using SVR, RSM and GA in hard turning of tempered AISI 1060 steel under effective cooling condition, Neural Comput. Appl. (2017). DOI: 10.1007/s00521-017-3192-4

31. D. Singh, P. Venkateswara Rao, Performance improvement of hard turning with solid lubricants, Int. J. Adv. Manuf. Technol. 38 (2008) 529-535

32. A.E. Diniz, J.R. Ferreira, F.T. Filho, Influence of refrigeration/ lubrication condition on SAE 52100 hardened steel turning at several cutting speeds, Int. J. Mach. Tools Manuf. 43 (2003) 317-326

33. M. Mia, P.R. Dey, M.S. Hossain, M.T. Arafat, M. Asaduzzaman, M. Shoriat Ullah, S.M. Tareq Zobaer, Taguchi S/N based optimization of machining parameters for surface roughness, tool wear and material removal rate in hard turning under MQL cutting condition, Measurement 122 (2018) 380-391

34. W.V. Leadebal, Jr., A.C.A. de Melo, A.J. de Oliveira, N.A. Castro, Effects of cryogenic cooling on the surface integrity in hard turning of AISI D6 steel, J. Braz. Soc. Mech. Sci. Eng. 40 (2018) 15

35. R. Suresh, S. Basavarajappa, Effect of process parameters on tool wear and surface roughness during turning of hardened 
steel with coated ceramic tool, Proc. Mater. Sci. 5 (2014) 1450-1459

36. R.W. Bin, S. Goel, J.P. Davim, S.N. Joshi, Parametric design optimization of hard turning of AISI 4340 steel (69 HRC), Int. J. Adv. Manuf. Technol. 82 (2016) 451-462

37. H. Bensouilah, H. Aouici, I. Meddour, M. Athmane, Performance of coated and uncoated mixed ceramic tools in hard turning process, Measurement 82 (2016) $1-18$
38. K. Bouacha, M.A. Yallese, T. Mabrouki, J.-F. Rigal, Statistical analysis of surface roughness and cutting forces using response surface methodology in hard turning of AISI 52100 bearing steel with CBN tool, Int. J. Refract. Met. Hard Mater. 28 (2010) 349-361

39. S.R. Das, A. Kumar, D. Dhupal, Experimental investigation on cutting force and surface roughness in machining of hardened AISI 52100 steel using cBN tool, Int. J. Mach. Mach. Mater. 18 (2016) 501-521

Cite this article as: Abhishek Anand, Ajay Kumar Behera, Sudhansu Ranjan Das, An overview on economic machining of hardened steels by hard turning and its process variables, Manufacturing Rev. 6, 4 (2019) 